\title{
Uncertainties for Swiss LWR spent nuclear fuels due to nuclear data
}

\author{
Dimitri A. Rochman*, Alexander Vasiliev, Abdelhamid Dokhane, and Hakim Ferroukhi \\ Laboratory for Reactor Physics Systems Behaviour, Paul Scherrer Institut, Villigen, Switzerland
}

Received: 27 October 2017 / Accepted: 14 March 2018

\begin{abstract}
This paper presents a study of the impact of the nuclear data (cross sections, neutron emission and spectra) on different quantities for spent nuclear fuels (SNF) from Swiss power plants: activities, decay heat, neutron and gamma sources and isotopic vectors. Realistic irradiation histories are considered using validated core follow-up models based on CASMO and SIMULATE. Two Pressurized and one Boiling Water Reactors (PWR and BWR) are considered over a large number of operated cycles. All the assemblies at the end of the cycles are studied, being reloaded or finally discharged, allowing spanning over a large range of exposure (from 4 to $60 \mathrm{MWd} / \mathrm{kgU}$ for $\simeq 9200$ assembly-cycles). Both $\mathrm{UO}_{2}$ and MOX fuels were used during the reactor cycles, with enrichments from 1.9 to $4.7 \%$ for the $\mathrm{UO}_{2}$ and 2.2 to $5.8 \% \mathrm{Pu}$ for the MOX. The SNF characteristics presented in this paper are calculated with the $S N F$ code. The calculated uncertainties, based on the ENDF/B-VII.1 library are obtained using a simple Monte Carlo sampling method. It is demonstrated that the impact of nuclear data is relatively important (e.g. up to $17 \%$ for the decay heat), showing the necessity to consider them for safety analysis of the SNF handling and disposal.
\end{abstract}

\section{Introduction}

The safe handling and storage of spent nuclear fuels (SNF) is a subject of active studies in many European countries. A large amount of SNF are stored in pools at the power plant sites, waiting to be moved to interim or long-term storage facilities. The handling of such an amount of fissile materials needs to be performed minimizing the potential contamination to the environment, as well as to ensure avoiding any critical configurations. Same goals are applied for the long-term storage of the SNF, while reaching solutions which are economically sound. In this context, neutronics simulations play a keyrole in calculating doses, fuel content and criticality possibilities, for various geometry, amounts, arrangements so that the best combination of safety and economy can be found. An example of such study performed for Swiss reactors and SNF is presented in reference [1].

In such simulations, the confidence in the final calculated quantities needs to be assessed taking into account all sorts of uncertainties, including the ones on the input data, such as the fuel burnup, or the amount of fissile materials. Such quantities are used to determine for instance if four, five, or six spent fuel assemblies can be safely loaded in a given canister, and if this canister can be

\footnotetext{
* e-mail: dimitri-alexandre.rochman@psi.ch
}

stored close to one, two or more of the same canister underground for a certain time (e.g. Ref. [2]). Some of the relevant quantities for storage are also calculated (such as the exposure of the assembly, or its fissile content), depending on the history of the involved assemblies. To take into account all sources of uncertainties in such calculations, there is a need for the quantification of the nuclear data impact. Nuclear data are part of the sources of uncertainties when performing the irradiation calculations of diverse assemblies, and it is not yet certain how large are such uncertainties on the different calculated quantities.

Up to now, there is no study on the uncertainties due to nuclear data on assembly burnup, decay heat, neutron and gamma sources, as well as isotope inventory for realistic fuel histories, in the case of the Swiss nuclear fuel. For instance in reference [3], a study on the radionuclide inventory in the fuel cladding for Swiss SNF is presented with a comparison between different calculation schemes, but such a study does not tackle the fuel activity. The characterization of the uncertainties due to nuclear data for the Swiss SNF is the aim of the present paper, where realistic models of fuel irradiations over many reactor cycles are considered. The present study is based on real Pressurized and Boiling Water Reactors (PWR, BWR), loaded with $\mathrm{UO}_{2}$ fuel assemblies (and MOX assemblies for the PWR), spanning over many years of service. A total of 9200 different fuel assemblies are studied, with exposure from 4 to $60 \mathrm{GWd} / \mathrm{tHM}$, when considering each of them at 


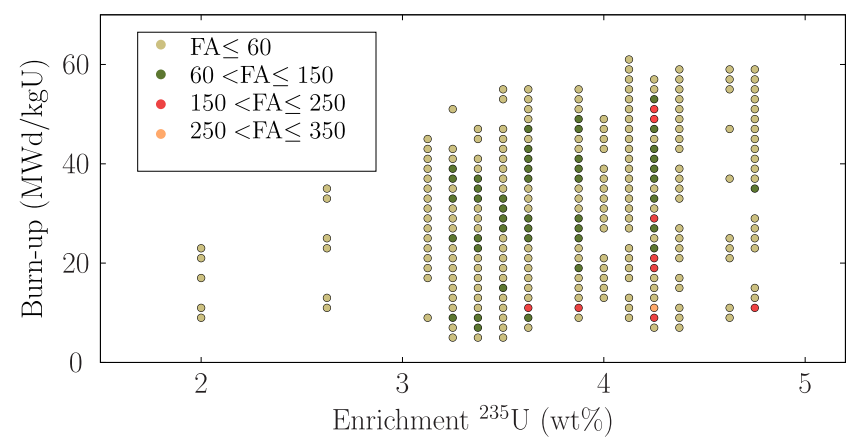

Fig. 1. Number of $\mathrm{UO}_{2}$ assemblies for the $3 \mathrm{LWR}$ (2 PWR and 1 BWR) considered in this work with their enrichment and burnup values. In total, 9200 assembly-cycles are studies. The MOX assemblies are not represented. In the insert, the number of fuel assemblies (FA) are presented by colours.

the end of all cycles. As an indication, Figure 1 schematically presents the number of assemblies with their burnup and enrichment values. One can see that the majority of assemblies are enriched at more than $3 \%$, with burnup values equally distributed from 10 to $60 \mathrm{MWd} / \mathrm{kgU}$ (not all of the studied assemblies qualify for final discharge).

The present study is performed with the CASMO and SIMULATE tool for the core simulations, and with the SNF code for the spent fuel. Uncertainties are calculated following a simple Monte Carlo method with random nuclear data based on the ENDF/B-VII.1 library. The results for activity, decay heat, neutron and gamma sources, as well as on the inventory for important isotopes are presented.

\section{Uncertainty propagation scheme}

In the following, we will describe the complete calculation flow to propagate nuclear data uncertainties from the production of the multigroup cross sections to the characteristics of the SNF. The method is based on covariance matrices coming from the ENDF/B-VII.1 library, simulations of $n$ cycles of operations of a real PWR or BWR core with CASMO and SIMULATE, and calculations of the fuel exposure, decay heat and other quantities with the $S N F$ code.

\subsection{Monte Carlo propagation}

The method of uncertainty propagation is relatively straightforward, once the calculation scheme is in place. It consists in repeating the nominal calculation a large number of times, each time with different input nuclear data. This method is based on the Total Monte Carlo approach [4]. Many applications of this method can be found in the literature for the criticality-safety, pincell calculations, or at the assembly level. Monte Carlo sampling was already applied to estimate specific uncertainties for nuclear waste (see Ref. [5]), but up to now, no study demonstrates the impact of nuclear data. In the case of the full core uncertainty propagation, the number of studies for uncertainty propagation is more limited due to the required computer power, see for instance references [6-8].

Repeating $n$ times the same calculation with different nuclear data allows to obtain $n$ times the same calculated quantities, such as the fuel exposure for a specific assembly. From the $n$ values, one can build probability density functions (pdf), with all the intrinsic moments such as the average and the standard deviation. Higher moments can be obtained, and are useful to characterize the pdf if it does not correspond to a Normal distribution. Such method has the disadvantage to require large computational power (typically, a single iteration takes between one and two days on a single modern computer core), but it leads to uncertainties on any calculated quantities, given the assumptions from the simulation tools and methods.

\subsection{Nuclear data}

The nuclear data considered in this work are all the cross sections, neutron emission and spectra included in the ENDF/B-VII.1 library [9]. In such library, covariance files are available for all the major isotopes, and 76 isotopes are considered in this work: from ${ }^{1} \mathrm{H}$ to ${ }^{244} \mathrm{Cm}$. Specific examples of uncertainties for a few fuel assemblies will be presented due to important isotopes: ${ }^{235} \mathrm{U},{ }^{238} \mathrm{U},{ }^{239} \mathrm{Pu}$, minor actinides, fission yields and light isotopes. The same list of isotopes was used in references [6,7]. The reactions with covariance files are elastic, inelastic, $(n, 2 n)$, capture, fission, plus the neutron spectra and neutron emission for the actinides.

For the fission yields, it is known that the existing libraries do not provide correlation matrices. This is nevertheless not practical for uncertainty propagation and different methods are proposed to sample fission yields taking into account some degree of correlations. Examples can be found in references [7,10]. In the present work, the method developed in reference [11] is applied. It consists in applying different physical constraints such as the summation rule, the mass and charge conservations and the complementarity of the nuclear charge. A correlation matrix is therefore built for a specific fissioning isotope, and uncertainties coming from a library are added to generate a full covariance matrix. One should keep in mind that in the absence of recommended covariance values in the evaluated libraries, a spread of results can be observed depending on the method used to produce such covariance matrices.

The ENDF/B-VII.1 covariance files are first processed with NJOY-2012 [12] into 19 energy groups, from thermal energy to $20 \mathrm{MeV}$. Using Cholesky decomposition of these matrices, random realizations of the above nuclear data were obtained following the joint probability distributions defined with Normal distributions. These mathematical steps, and the formatting of the final random nuclear data are performed with the SHARK-X tool [13]. It also allows to provide these nuclear data to a modified version of the CASMO-5 code [14]. This version is similar to the standard CASMO-5, with the modifications of the subroutines for accessing the nuclear data (details can be found in reference [15]). This way, nuclear data for cross sections, spectra and 


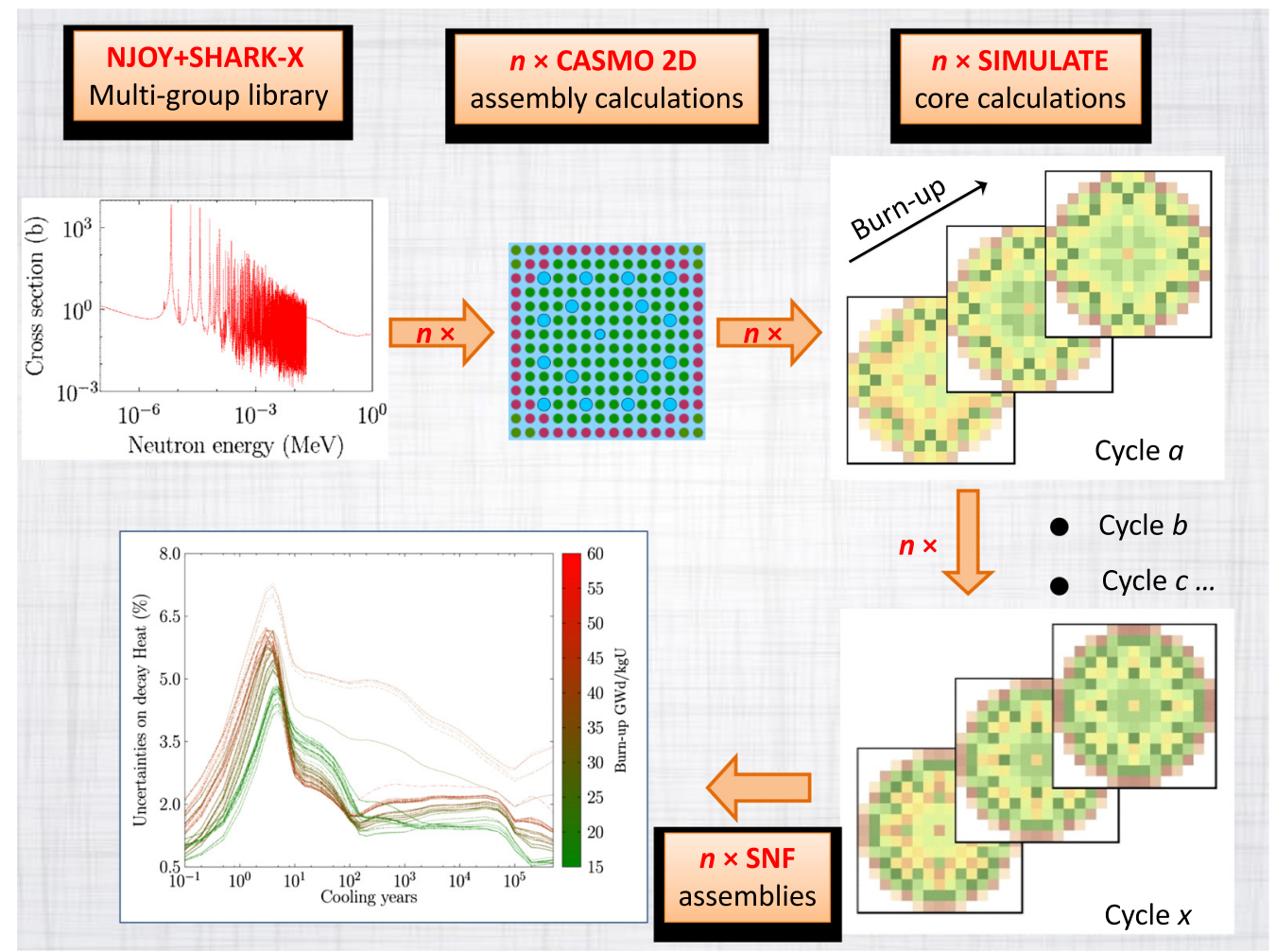

Fig. 2. Schematic view of the simulations from basic nuclear physics quantities to spent fuel characteristics. Each calculation chain is performed $n$ times, each time changing the nuclear data as input values.

prompt neutron emission can be changed prior to the lattice calculations, based on any covariance matrices. Other nuclear data, such as angular distributions or thermal scattering data are not modified.

As observed in many publications, the effect of the uncertainties for the decay data (such as half-lives, $Q$ values, decay types) is relatively limited and negligible compared to the effects of the uncertainties for cross sections or fission yields [16-18].

\subsection{Realistic LWR cores}

The above methodology is applied to realistic LWR cores, loaded with $\mathrm{UO}_{2}$ and MOX fuel for different enrichments. The simulations of the neutronics parts of the core is performed with SIMULATE-3 or SIMULATE-5 [19] depending on the LWR core, for a number of successive cycles, spanning over many years of operations. Such CASMO and SIMULATE models are based on validated reactor history and simulation using the LWR information as provided by the plant operator: fuel assembly design, fuel loading patterns, power history, boric acid concentrations, shutdown periods, etc. In this work, the different validated models are not changed and the calculated uncertainties only correspond to the variations of nuclear data, keeping constant all other model parameters (such as the axial meshing, the time/burnup calculation steps and the total core power). The scheme of calculations is presented in Figure 2. The following three main steps are important for the simulations performed in this work. After the preparation of the nuclear data in a form ready to be used, the lattice calculations with the modified version of CASMO-5 are performed. These calculations are realized for each assembly type, based on the information on the fuel assemblies and produces multigroup cross sections and discontinuity factors. Such calculations at the assembly level are then passed to the core simulator, where the actual full core simulation happens. Based on the assembly data provided by CASMO-5, and other quantities such as a simplified power history (coming from the plant operator), or the running and shutdown times, the core behavior is simulated over many cycles with SIMULATE.

Finally, all the assembly histories from SIMULATE and cross sections from CASMO-5 can be used to calculate the SNF characteristics (decay heat, gamma and neutron emission, and isotope inventory) using the $S N F$ code [20]. The $S N F$ code can be used at the end of each cycle, even if the assembly is not discharged for storage. In such a way, the characteristics for all assemblies, being irradiated for one cycle or more, can be calculated, leading to different quantities for a variety of exposure values.

This is the proposed calculation scheme, using these three above codes with realistic data from Swiss LWRs loaded with $\mathrm{UO}_{2}$ and MOX fuels. These simulations are performed for the cases presented in Table 1. Considering the SNF calculations at the end of each cycle, about 9200 assembly burnup values (exposure) are obtained from 4 to $60 \mathrm{MWd} / \mathrm{kgU}$.

The name assembly-cycles is used to define a specific assembly at the end of a specific cycle. For instance, if an assembly is inserted in a core for 3 cycles, the assemblycycles value counted in Table 1 is 3 . 
Table 1. Characteristics of the simulated Swiss LWR cores considered in this work. "Other" means all nuclear data except fission yields (which are separately varied), see Section 3 for details. "FY" means fission yields. The MOX enrichment is given for all $\mathrm{Pu}$ isotopes.

\begin{tabular}{lllllllll}
\hline $\begin{array}{l}\text { Core } \\
\text { label }\end{array}$ & Type & Fuel & $\begin{array}{c}\text { Enrichment } \\
\%\end{array}$ & Cycles & $\begin{array}{c}\text { Assembly- } \\
\text { cycles }\end{array}$ & \multicolumn{2}{c}{$\begin{array}{l}\text { Burn-up } \\
\text { MWd/kgU }\end{array}$} & \multicolumn{2}{c}{$\begin{array}{l}\text { Random cases } n \\
\text { FY }\end{array}$} & Other \\
\hline PWR-1 & PWR & $\mathrm{UO}_{2}$ & $2.9-4.7$ & $17-42$ & 2542 & $4-60$ & 320 & 110 \\
PWR-1 & PWR & MOX & $2.2-5.8$ & $17-42$ & 297 & $4-50$ & 320 & 110 \\
PWR-2 & PWR & $\mathrm{UO}_{2}$ & $1.9-3.5$ & $1-16$ & 2647 & $7-55$ & 110 & 100 \\
BWR-1 & BWR & $\mathrm{UO}_{2}$ & $0.7-4.5$ & $19-44$ & 3746 & $10-45$ & 35 & 35 \\
\hline
\end{tabular}

Once such a calculation chain is in place, it is repeated $n$ times, each time randomly changing the nuclear data libraries. For practical reasons, the variation of the fission yields is separated from the variations of the other nuclear data. We then first perform a set of $n$ calculations varying all nuclear data but the fission yields, and separately repeat another $n$ calculations, this time only randomly changing the fission yields.

In the following, the total uncertainty is presented, being the independent sum of the variances:

$$
\text { uncertainty }=\sqrt{\sigma_{\mathrm{FY}}^{2}+\sigma_{\mathrm{other}}^{2}} \text {. }
$$

It is then assumed that no correlation exists between the observables due to the variations of fission yields and the other nuclear data.

\section{Results}

In the following, we will present the results in terms of average $(x)$, standard deviation $(\sigma)$ and correlation $(\rho)$. The usual following equations are used, where $x_{i}$ represents the $i$ random realization for the quantity $x$ (for instance the decay heat), with $i=1 \ldots n$ :

$$
\left\{\begin{array}{l}
\bar{x}=\frac{1}{n} \sum_{i}^{n} x_{i} \\
\sigma=\sqrt{\frac{1}{n} \sum_{i}^{n}\left(x_{i}-\bar{x}\right)^{2}} \\
\rho(x, y)=\frac{\sum_{i}^{n}\left(x_{i}-\bar{x}\right)\left(y_{i}-\bar{y}\right)}{\sqrt{\sum_{i}^{n}\left(x_{i}-\bar{x}\right)^{2} \sum_{i}^{n}\left(y_{i}-\bar{y}\right)^{2}}}
\end{array} .\right.
$$

\subsection{Calculated quantities}

Different spent fuel quantities will be presented in the following and correspond to the values provided by the SNF code. These are the uncertainties for the activity, decay heat, the neutron and gamma-ray emission and the isotopic vectors for a selection of important isotopes. All the uncertainties are expressed in terms of one standard deviation $(1 \sigma)$ from the above mentioned equations. Note that some isotopes above ${ }^{244} \mathrm{Cm}$ might be the main contributors to specific calculated quantities, for specific decay periods. Such isotopes are considered for the calculations of the SNF quantities, but their nuclear data are not randomly changed, e.g. ${ }^{246} \mathrm{Cm}$.

An example for the calculated decay heat and activity (not the uncertainty) is presented in Figure 3, for a specific BWR fuel assembly, used over many cycles.

The decay heat and the activity are presented for two burnup values: the first one $(11 \mathrm{MWd} / \mathrm{kgU})$ is obtained after the first reactor cycle where this assembly is used. An hypothetical storage is considered and leads to the decay curves of Figure 3. The second set of curves is obtained after the use of this assembly in 6 consecutive cycles, leading to a burnup value of $53 \mathrm{MWd} / \mathrm{kgU}$. Such curve is useful to observe which are the important contributors to the nominal, mean and standard deviation for the decay heat. As observed, the fission products are the main contributors below $\simeq 100$ years.

In the following, uncertainties due to nuclear data will be presented based on decay heat curves as presented in Figure 3. The neutron and gamma emissions (in particle per second and ton) are presented in Figures 4 and 5 and used in a similar manner. In the $S N F$ code, the neutron sources in spent fuel are due to spontaneous fission of certain actinides and $(\alpha, n)$ reactions in oxide fuel due to alpha particles from alpha-emitting actinides. In the case of the neutron emission, the contributions for the main actinides are also presented. If the number of emitted neutrons strongly increases with the value of the burnup, the contributors are also changing, with a higher number of emissions from heavier actinides. One can notice the preponderance of ${ }^{244} \mathrm{Cm}$ at high burnup up to $\simeq 100$ years.

In the case of the gamma emission, the number of emitted gamma is not strongly increasing with burnup. The uncertainty on this quantity is presented in the following, but contrary to the neutron case, the contributions of different isotopes are not presented.

It is also interesting to present the isotopic compositions as a function of cooling time for a specific assembly. This helps to assess which are the existing isotopes at specific period of time. In the case of a BWR assembly with $\mathrm{UO}_{2}$ fuel enriched at $4.2 \%$, the isotopic compositions are presented in Figure 6 for a burnup of $43 \mathrm{MWd} / \mathrm{kgU}$. One can see the evolution of the actinides, as well as the importance of the fission products. As mentioned later in Section 3.7, one current limitation of the $S N F$ version used in this work (version 1.6) is that not all stable fission products are accounted for, as they do not contribute to the 

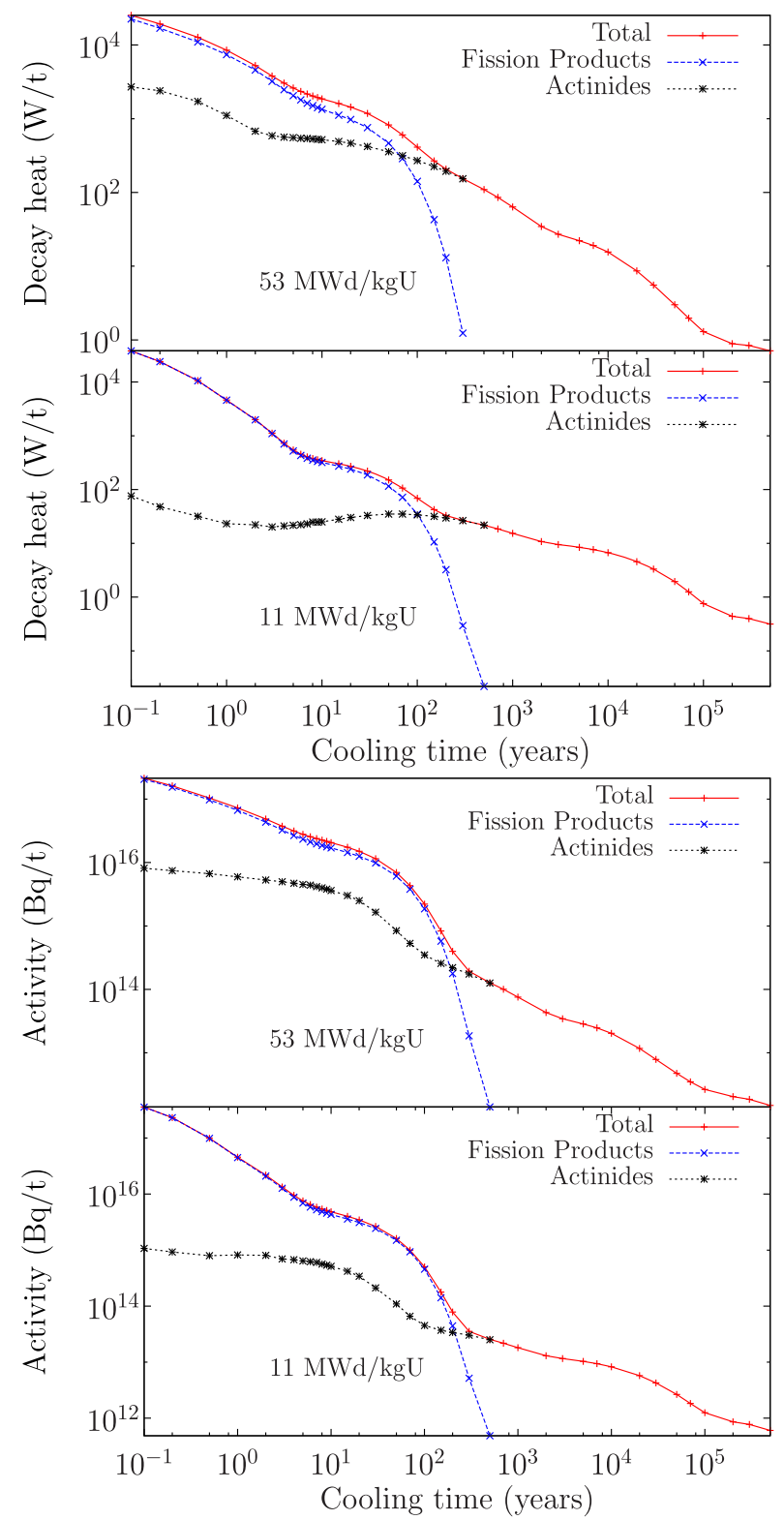

Fig. 3. Top: calculated decay heat for a typical BWR $\mathrm{UO}_{2}$ assembly at two different burnup values. The highest one corresponds to the actual final discharge. Bottom: same for the assembly activity.

decay heat or activity of the SNF. Therefore one can see in Figure 6 that the amount of fission products is decreasing with cooling time, which is an artificial effect.

In conclusion, the uncertainties presented in the following will be based on the variations of these quantities when changing the nuclear data.

\subsection{Statistical convergence}

The calculation chain from the generation of the nuclear data to the production of the SNF quantities is relatively computer intensive. As such, the different codes involved in this approach cannot be run in parallel mode for a single

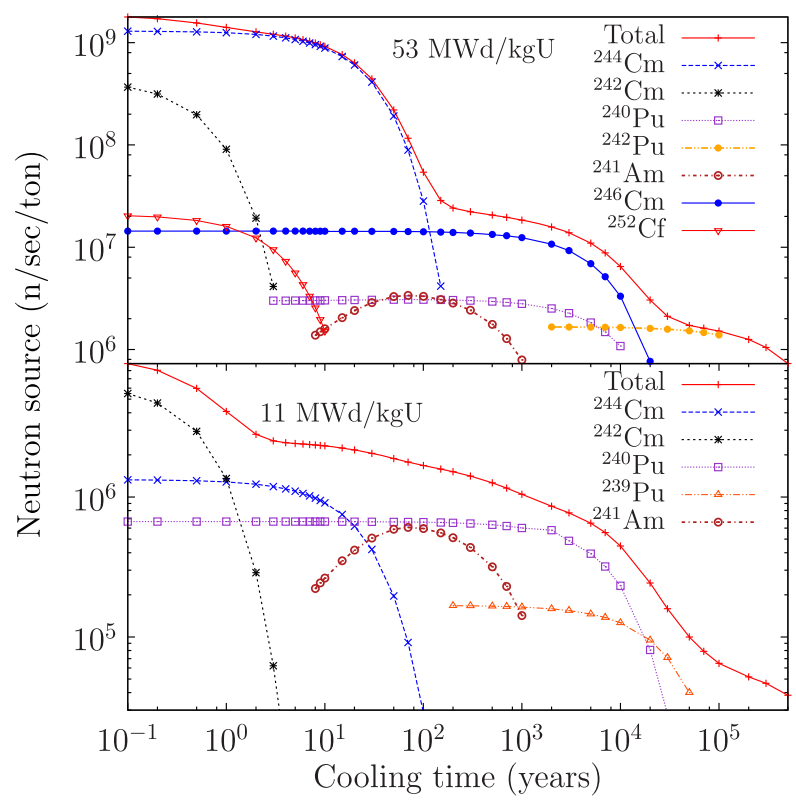

Fig. 4. Similar to Figure 3 but for the neutron emissions.

calculation, which prevent the use of large computer cluster where the scalability is an important criteria. On the other hand, the advantage of this Monte Carlo approach is that each realization (one calculation chain based on a realization of the random nuclear data) is independent of each other, allowing to perform a number of calculations on independent computer cores.

Depending on the size and type of the reactor core, a single calculation chain can last 3 weeks for many cycles. Given the available computer power with the validated models and codes, a limited number of samples could be achieved, as indicated in Table 1. As in any Monte Carlo process, the convergence of the results is an important criteria. If $n$ is the number of samples, the standard error on the calculated mean varies as $\sigma / \sqrt{n},(\sigma$ is the standard deviation) whereas the standard error on the standard deviation varies as $\sigma / \sqrt{2 n}$. Alternatively, the standard error on the skewness can be approximated by $\sqrt{\frac{6 n(n-1)}{(n+1)(n+3)(n-2)}}$, and for the correlation $\rho: \frac{1-\rho^{2}}{\sqrt{n-1}}[21,22]$.

In the following, results on the standard deviation will be presented, and using the above formula, one can calculate the largest standard error: in the case of the core number 3 , with a total of 35 samples, one obtains a standard error of about $12 \%$. This means that the presented standard deviations have a maximum statistical uncertainty due to the number of samples of about $12 \%$. One should noticed that from this limited number of samples, it is rather difficult to extract correlation values with some input parameters (e.g. cross sections) with confidence: for instance, for a correlation of 0.1, the standard error is about 0.2. Similar comment applies to the skewness of the calculated quantities. On the contrary, correlations between calculated quantities can be obtained. In this case, as a large number of assemblies are considered for each reactor, the correlation $\rho$ between calculated SNF quantities can be obtained with a small standard deviation. 


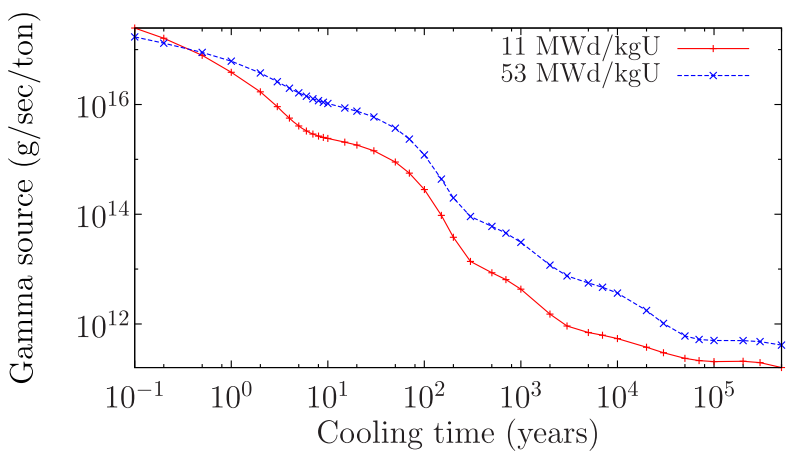

Fig. 5. Similar to Figure 3 but for the number of emitted gamma.

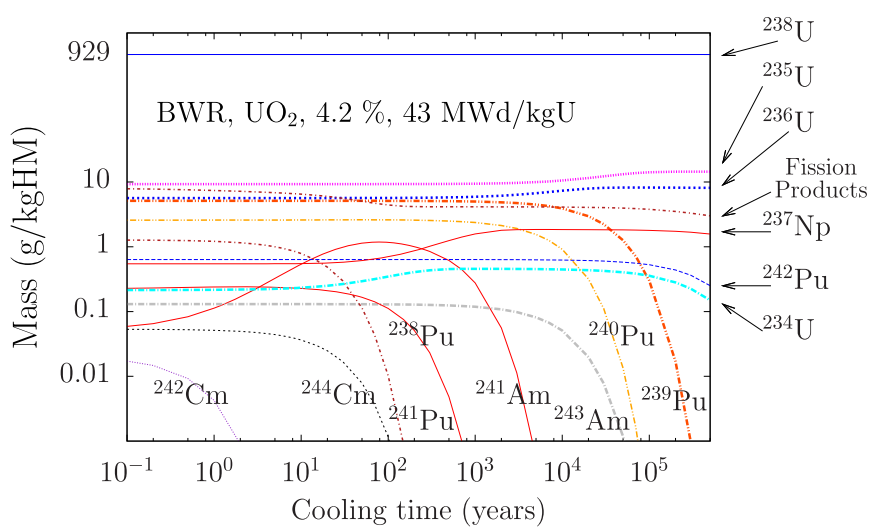

Fig. 6. Similar to Figure 3 but for the isotopic contents.

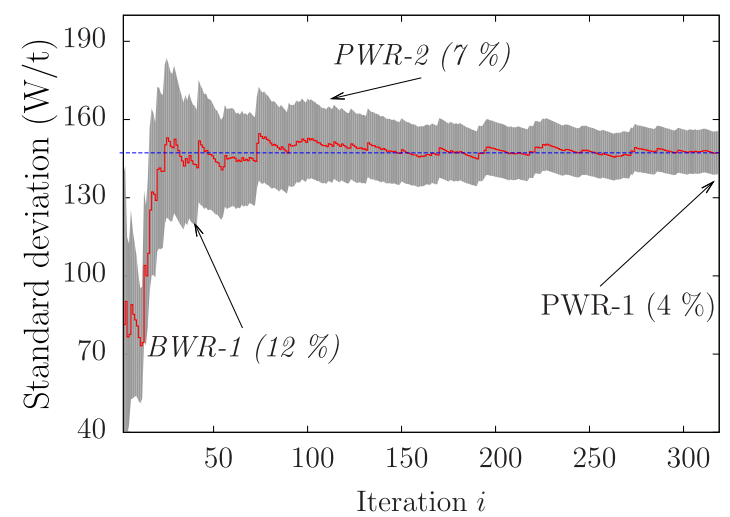

Fig. 7. Example of the convergence of the standard deviation on the decay heat for a particular assembly at a specific cooling time in the case of the core PWR-1. As an indication, the values obtained for other $i$ values are presented by two arrows, thus simulating the maximum iteration for the other cores. The shadow band represents the standard error on the standard deviation. The red line is the running standard deviation and the blue line is the final standard deviation after 320 iterations.

Figure 7 presents an example of the convergence of the standard deviation for the decay heat of a particular assembly as a function of the number of samples in the case of the PWR-1.
From the figure, one can also see as an indication the standard errors for the two other reactors considered: whereas the case of the PWR-1 core is presented (with more than 320 iterations), the values obtained for lower iterations are indicated by arrows: for $i=35$ and $i=110$, indicating the values for the two other cores: the PWR-2 and BWR-1.

\subsection{Nuclear data decomposition}

For a limited number of assemblies, the variations of the nuclear data was separately performed for the major isotopes in 6 different groups: ${ }^{238} \mathrm{U},{ }^{235} \mathrm{U},{ }^{239} \mathrm{Pu}$, minor actinides, light isotopes and fission yields. Other isotopes, such as fission products have a small impact on uncertainties. The results of the different components are presented in Figure 8 for a PWR case with $\mathrm{UO}_{2}$ fuel for the decay heat, the neutron/gamma sources (at $35 \mathrm{MWd}$ / $\mathrm{kgU}$ ) and the fuel exposure. As presented in this figure, the impact of nuclear data varies depending on the studied quantities:

- In the case of fuel exposure, the impact of nuclear data is rather limited with a maximum value for low burnup. The observed tendency is a decrease of uncertainties for increasing burnup. The main contributor to the uncertainties is in all cases the ${ }^{238} \mathrm{U}$, followed by fission yields.

- The impact on neutron and gamma emission is relatively different in shape, but is significant with maxima about 6 and 10\%. The minor actinides play an important role for neutron emission (with ${ }^{244} \mathrm{Cm}$ and ${ }^{240} \mathrm{Pu}$ at short and long cooling time, respectively), but also in the case of gamma emission for long cooling years (above 1000 years). In the case of the gamma emission, the impact of the fission yields is substantial below 100 200 years.

One should note that the neutron and gamma emission are here varied following the provided covariance matrices, which do not take into account the uncertainties in particle emission and spectra from decaying isotopes (such as metastable states). Only the isotope compositions through cross sections, fission neutrons and their spectra are included in the covariance files. For a more exhaustive result, a method such as the Total Monte Carlo approach should be considered [4].

- The decay heat uncertainties are strongly influenced by the fission yields (below 100 years) and ${ }^{238} \mathrm{U}$ (after 100 years). The fission yields directly affect the amount of fission products (and therefore the gamma emission) at short cooling time (below 10 years), therefore being a major contributor for both the decay heat and the gamma emission. For longer cooling time, as the majority of fission products emitting gammas have decayed, the contribution of actinides become more important, such as ${ }^{239,240} \mathrm{Pu}$ coming from the build-up from ${ }^{238} \mathrm{U}$ during irradiation.

This specific example indicates the importance of the impact of the nuclear data on the SNF quantities. As indicated, the significant sources of uncertainties for decay 

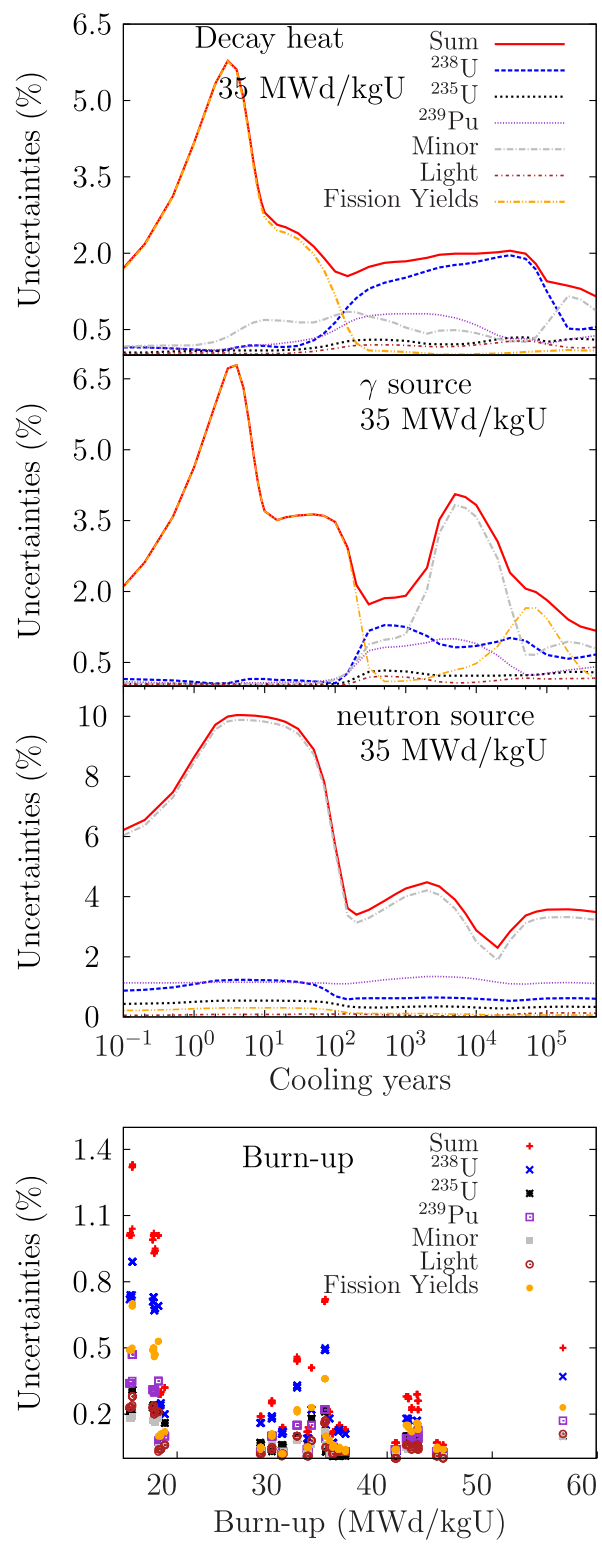

Fig. 8. Example of uncertainty decomposition for four SNF quantities: decay heat, gamma and neutron emission and fuel exposure (Burn-up) for one of the PWR cores with $\mathrm{UO}_{2}$ fuel. For the decay heat and gamma/neutron emission, the assembly exposure is $35 \mathrm{MWd} / \mathrm{kgU}$.

heat or neutron/gamma emission are various, from fission yields to cross sections for heavy actinides. As a useful information for experimentalists and the high-priority request list for measurements, it will be interesting to perform a breakdown of the uncertainties per isotopes and possibly per reactions. This could not be achieved in this work because of limited computer resources, but is technically feasible.

In the following, results for all the considered cases will be presented in a condense manner. If this paper does not allow to extract specific information for each particular assembly and core type, it shows an overview and helps to assess the global impact of nuclear data. For convenience, summary tables are presented in the Appendix.

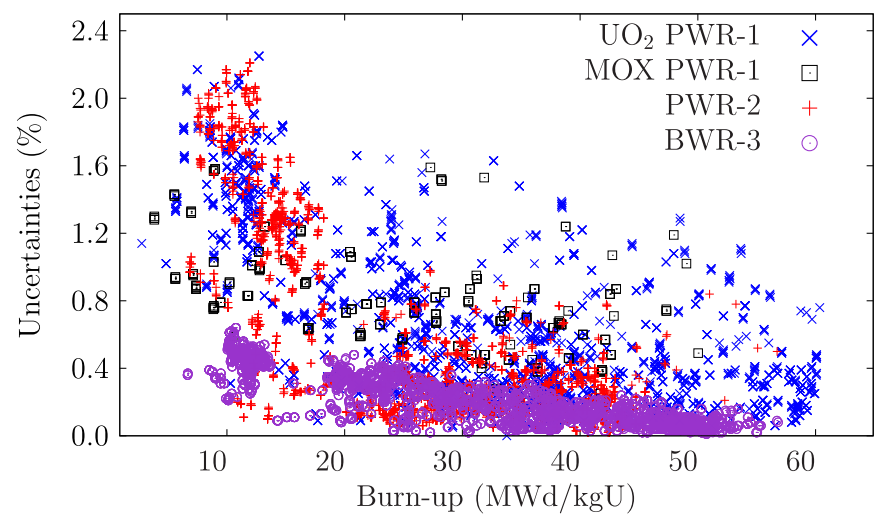

Fig. 9. Uncertainties on the assembly burnup for different exposures, for all assemblies in different cores (PWR and BWR), with $\mathrm{UO}_{2}$ and MOX fuel.

\subsection{Fuel exposure}

The fuel exposure is an important calculated quantity and is not directly measured. It is nevertheless a quantity which is often refereed to when characterizing spent fuel assemblies during or after irradiation. Figure 9 presents the uncertainties on the calculated burnup values. The burnup values of individual assemblies are changing due to the change in nuclear data and the constant total core power (which is fixed in the validated models). Two main points can be noticed: (1) the maximum uncertainty is about $2.4 \%$, and (2) there is a weak trend of decreasing uncertainties with higher burnup values.

Looking more into the details, there does not seem to be strong differences between $\mathrm{UO}_{2}$ and MOX fuel (for a PWR core), but there appears to be a noticeable difference between the PWR and BWR results. The uncertainties for the BWR assemblies are much smaller than for the PWR cases, with a maximum value of about $0.5 \%$. This effect is certainly due to the difference of calculation method between a PWR and BWR. Whereas the boron concentration is adjusted along the cycle calculation for a PWR (fixed $k_{\text {eff }}=1$ ), this is not the case for a BWR where all the conditions remain the same (but $k_{\text {eff }}$ vary): from one set of CASMO cross sections to another one (different random cases), the PWR cycle calculations are not identical (due to the boron adjustment in SIMULATE), changing the burnup of each assembly. For a BWR, there is no internal adjustment, the burnup of each assembly is almost not changed, contrary to the $k_{\text {eff }}$ value.

Regarding the decreasing trend, it is much more pronounced in the case of the BWR. This indicates a "fading away" of the effect of nuclear data, showing that after 25 cycles, the burnup values of all assemblies are sensibly the same as a function of nuclear data.

In all the studied cases, the impact of nuclear data is rather limited, and other sources of uncertainties (such as the irradiation history or the moderator temperature and density) can also have an important impact. 

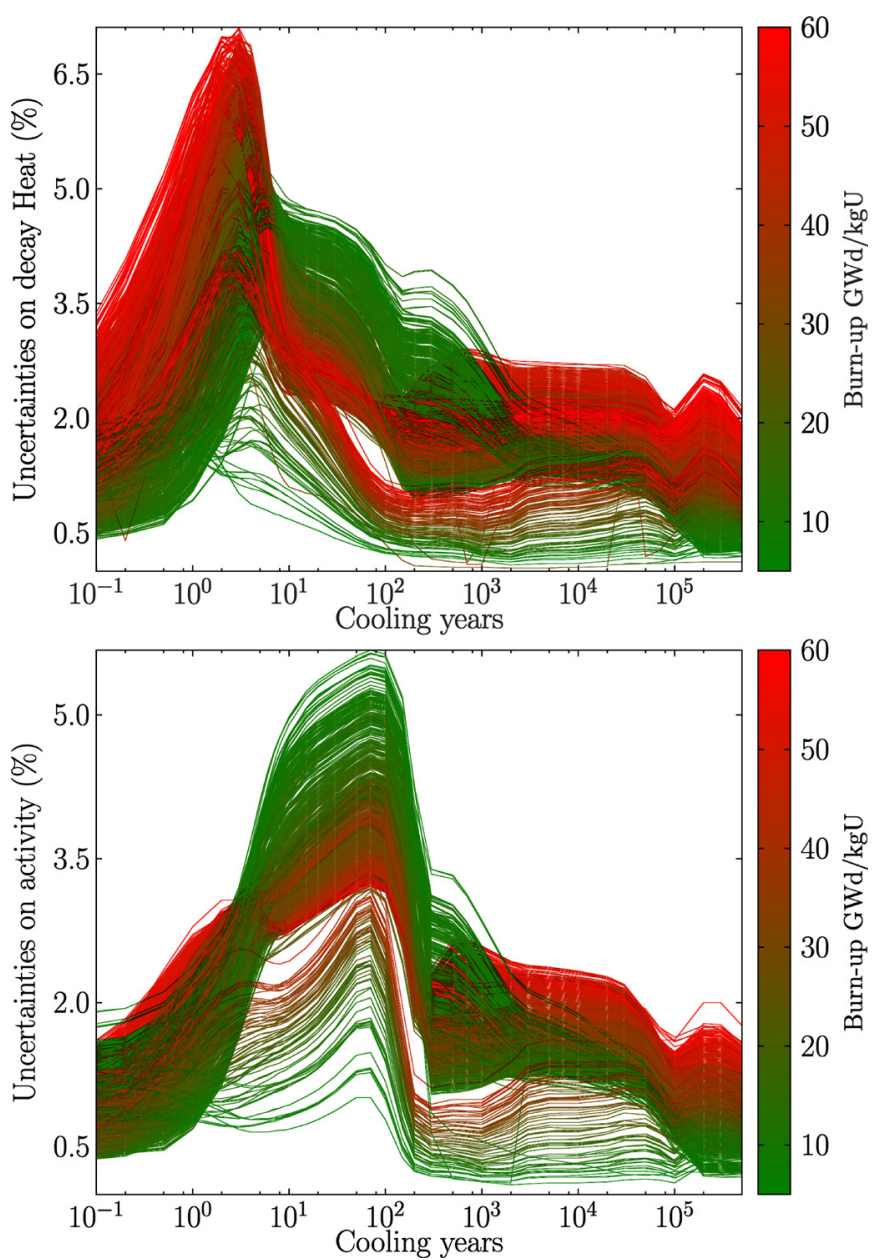

Fig. 10. Top: uncertainties on decay heat due to nuclear data, for the three different cores (PWR and BWR). One curve represents one assembly at the end of a specific cycle. Bottom: same for the activity. More than 9200 assemblies-cases are presented in each plot. Colours are proportional to the burnup values (right scale).

\subsection{Decay heat and activity}

The decay heat and activities presented in the following is calculated by the $S N F$ code. In Figure 10, the uncertainties are presented for different assemblies as a function of the cooling time: a single curve represents the uncertainty for the decay heat or activity due to nuclear data, for a specific assembly and the colour of the curve indicates the value of the assembly exposure (burnup).

As presented, the impact of nuclear data on the decay heat is larger than on the burnup values, with a maximum value of $7 \%$ at about a few years after irradiation. This is mainly due to the gamma emission by the fission products. It is also interesting to notice that the shape of the decay heat does not strongly change for different burnup values. As indicated in Table A.2, the uncertainty in the case of the MOX fuel is lower than for the $\mathrm{UO}_{2}$ fuel for both the decay heat and activity. It is also worth noticing that the maximum calculated uncertainty for the decay heat and the activity is obtained at the end of a typical cooling time
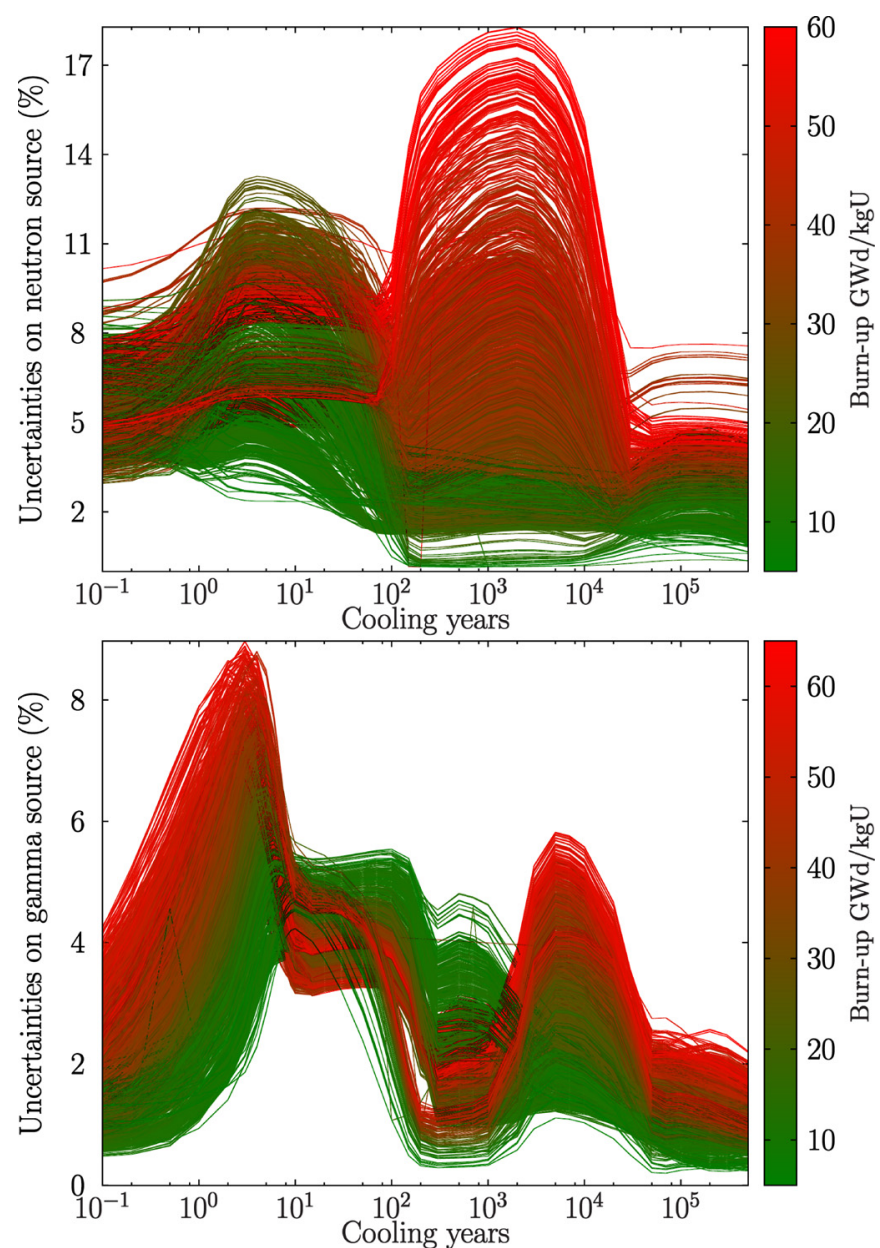

Fig. 11. Top: uncertainties on neutron source, for the three different cores. One curve represents one assembly at the end of a specific cycle. Bottom: same for the gamma source.

in wet storage (between 1 and 100 years). This is an accidental coincidence, which can increase penalty factors for the transport cask.

\subsection{Neutron and gamma source}

The neutron and gamma source uncertainties due to nuclear data are presented in Figure 11. They globally follow the shape presented in Section 3.3, and can reach relatively high values. These results are certainly strongly correlated with the decay heat uncertainties presented in Figure 10, which represents a weighted combination of the gamma and neutron effects.

Contrary to the decay heat, the neutron source uncertainty is strongly increasing with the assembly burnup, showing a maximum around 1000 years. With the general increasing trend of higher burnup for SNF at discharge in recent years, the calculated uncertainties for recent SNF is higher than for SNF used a few decades ago (with lower burnup values). As in the case of the decay heat, such high uncertainties, mainly due to ${ }^{244} \mathrm{Cm}$ for the first decades of cooling time (and ${ }^{242} \mathrm{Cm}$ for assemblies with low burnup values for the first few years) can also be at the 

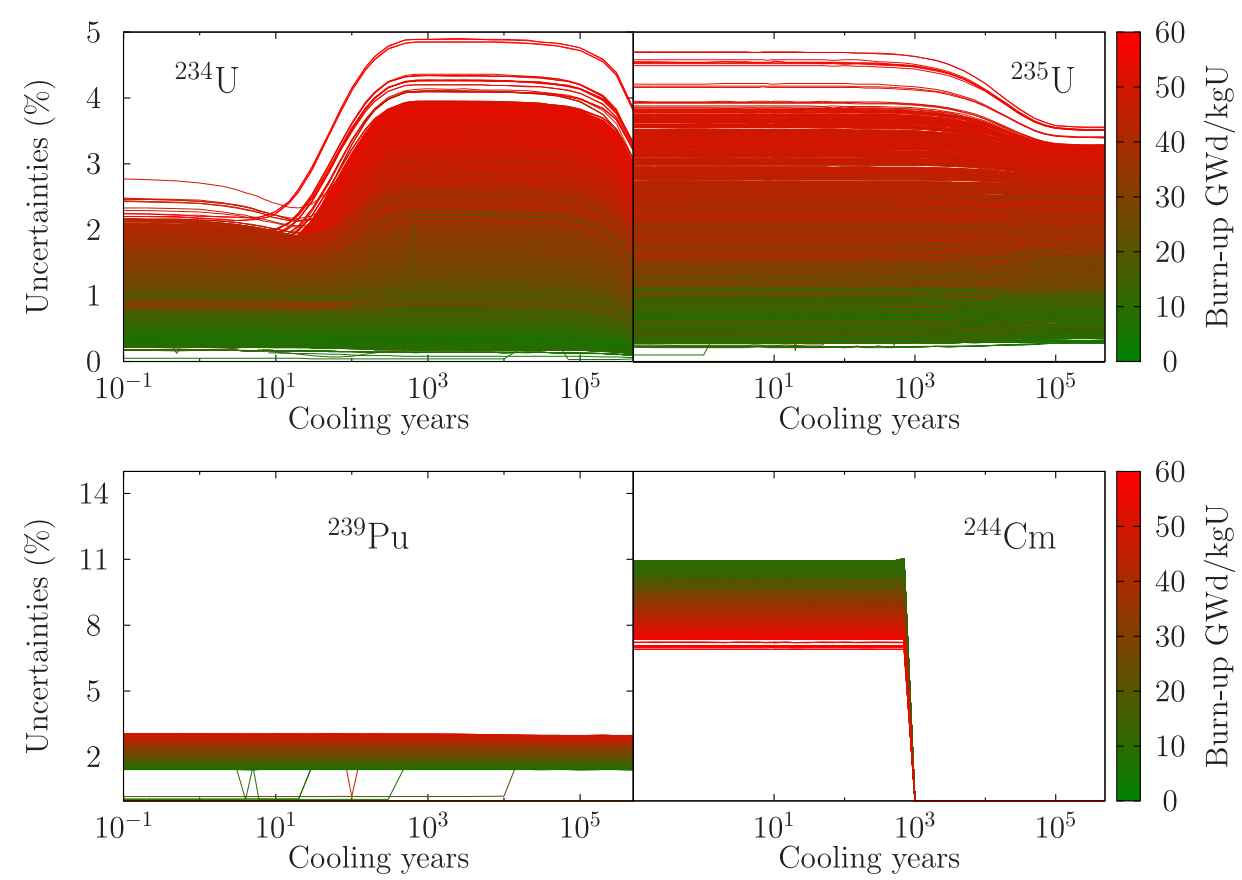

Fig. 12. Uncertainties for the number densities for 4 different isotopes $\left({ }^{234,235} \mathrm{U},{ }^{239} \mathrm{Pu}\right.$ and $\left.{ }^{244} \mathrm{Cm}\right)$, for the three different cores. One curve represents one assembly at the end of a specific cycle.

basis of the penalty factors for transport and storage. The improvement of the nuclear data for the isotopes leading to these curium nuclides should be of interest for the reactor community.

\subsection{Isotope inventory}

The $S N F$ code allows to extract the isotopic content for each assembly for a limit number of isotopes. All important actinides can be obtained, but with the current version of the $S N F$ code (version 1.6.4), a limited number of fission products can be extracted. In the following, the attention will therefore be put on four actinides (see Fig. 12).

In general, the variation of shape for the actinide uncertainties during cooling time depends on the half-life of the actinide itself or of its precursors. In the case of heavy actinides, such as the curium isotopes, as they do not have precursors during the decay, their uncertainties are relatively stable until they decay and disappear.

For ${ }^{234} \mathrm{U}$ and ${ }^{235} \mathrm{U}$, the variations of uncertainties come from the decay of ${ }^{238} \mathrm{Pu}$ and ${ }^{239} \mathrm{Pu}$, respectively. For the isotope inventory too, the impact of nuclear data is not negligible. In the case of ${ }^{244} \mathrm{Cm}$, an important neutron source for cooling time shorter than 50-100 years, the impact of nuclear data can be as high as $12 \%$, in agreement with previous studies $[11,23]$. In the case of ${ }^{235} \mathrm{U}$, the impact of nuclear data is also relatively important, varying from 0.4 to $4 \%$ depending on the assembly burnup value.

\subsection{Correlation}

As mentioned in Section 3.2, it is possible to calculate the correlation matrix between different quantities as a function of the cooling time. Such quantity was already

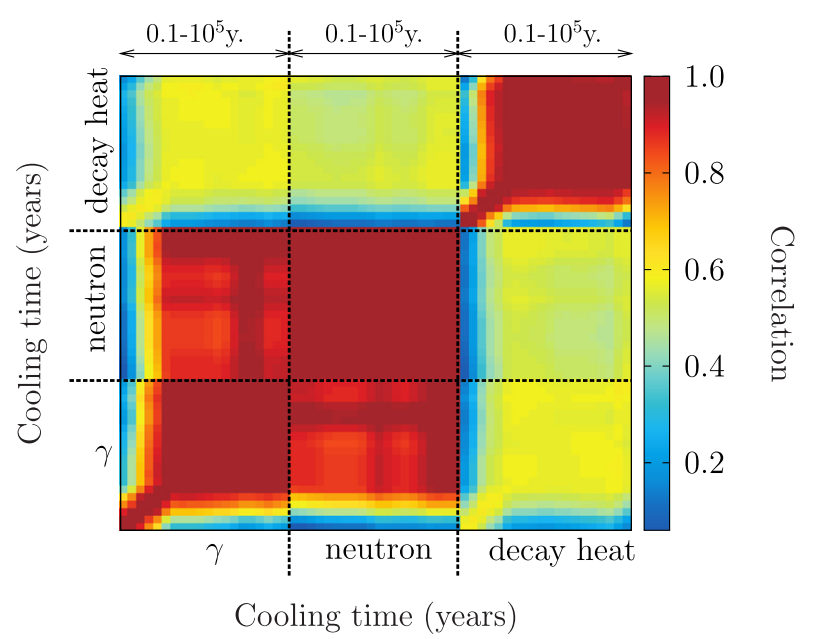

Fig. 13. Correlation matrix between the neutron emission, gamma emission and the decay heat (3 main blocks) for the PWR-2 $\left(\mathrm{UO}_{2}\right)$ core. Each quantity is represented for 20 cooling times from 0.1 to $5 \times 10^{5}$ years.

calculated for nuclear data only in reference [24] and for the decay heat as a function of the cooling time in reference [10]. As an example, the correlation between the neutron source, gamma source and the decay heat for the PWR-2 $\left(\mathrm{UO}_{2}\right)$ is presented in Figure 13, for cooling time from 0.1 to $5 \times 10^{5}$ years.

For each individual quantity (for instance for the neutron block), there is a relatively strong correlation, meaning that a quantity is strongly correlated with itself for different cooling time: variations at short time will be propagated at longer cooling time. 
Table 2. Comparisons with the uncertainties presented in reference [16]. "FY" means fission yields and "Other" means other nuclear data (cross sections, emitted neutron spectra and neutron emission).

\begin{tabular}{|c|c|c|c|c|c|c|c|c|}
\hline Core & $\begin{array}{l}\text { Cooling } \\
\text { (years) }\end{array}$ & $\begin{array}{l}\text { Burn-up, } \\
\mathrm{MWd} / \mathrm{kgU}\end{array}$ & $\begin{array}{l}\text { Enrichment } \\
\text { wt.\% }\end{array}$ & Geometry & Reference & Source & $\begin{array}{l}\text { Uncertainty } \\
\%\end{array}$ & Ref. \\
\hline BWR & 15.6 & 36.9 & 2.9 & 88 & 6432R1 & $\begin{array}{l}\text { FY } \\
\text { Other } \\
\text { Total }\end{array}$ & $\begin{array}{l}0.26 \\
0.88 \\
0.92\end{array}$ & [16] \\
\hline BWR & 15.0 & 37.3 & 3.0 & 1010 & Assembly-1 & $\begin{array}{l}\text { FY } \\
\text { Other } \\
\text { Total }\end{array}$ & $\begin{array}{l}2.31 \\
0.59 \\
2.3\end{array}$ & This work \\
\hline BWR & 15.0 & 36.8 & 3.0 & 1010 & Assembly-2 & $\begin{array}{l}\text { FY } \\
\text { Other } \\
\text { Total }\end{array}$ & $\begin{array}{l}2.20 \\
0.56 \\
2.3\end{array}$ & This work \\
\hline BWR & 15.0 & 36.8 & 3.0 & 1010 & Assembly-3 & $\begin{array}{l}\text { FY } \\
\text { Other } \\
\text { Total }\end{array}$ & $\begin{array}{l}2.24 \\
0.56 \\
2.3\end{array}$ & This work \\
\hline BWR & 15.0 & 36.8 & 3.0 & 1010 & Assembly-4 & $\begin{array}{l}\text { FY } \\
\text { Other } \\
\text { Total }\end{array}$ & $\begin{array}{l}2.24 \\
0.56 \\
2.3\end{array}$ & This work \\
\hline
\end{tabular}

The correlation between the neutron and gamma emission is also very strong, indicating that these quantities vary in the same manner: if one increases, the other one will also increase. Naturally the decay heat is also correlated with the neutron and gamma emission. The relatively equal cross-correlation blocks between the decay heat and the other quantities show that they both contribute to the decay heat.

One can also notice two main zones of weak correlation: at short cooling time for the gamma emission and for the decay heat. Such behaviour indicates a change in model calculation from one cooling period (short) to another one: below 3 days, $S N F$ calculates the decay heat of the shortlived fission products with the ANS-5.1 Standard [25] whereas the remaining isotopes are calculated with the summation method.

\section{Literature comparison}

The comparison of calculated uncertainties is relatively easy to do, but it is more difficult to draw conclusions. Many parameters can strongly influence a sequence of calculations, not only the input (such as nuclear data), but also the type of simulation (single assembly or full core), number of cycles, or the parameters during the simulations (operating conditions [7]). The present calculations offer the advantage to consider realistic assemblies, cycles and core configurations. But it is therefore difficult to compare such data with existing studies of the nuclear data impact as they are often performed in the context of "single assembly approximation", with reflective boundaries. Examples of such studies can be found in references [7,16,26-30], which is certainly not an exhaustive list (many additional references can be found for the study of the $k_{\text {eff }}$ uncertainty due to nuclear data, which is not a relevant subject in the case of a PWR full core study).

\subsection{Decay heat}

Calculations of the decay heat uncertainties for a $\mathrm{UO}_{2} 8 \times 8$ BWR assembly labeled $6432 R 1$ is presented in reference [16]. Comparisons with assemblies having characteristics close to this one for the present BWR are presented in Table 2. In the large number of BWR assemblies studied here, only 4 of them have burnup and enrichment values close to the values from reference [16].

As presented in Table 2, the four assemblies labeled Assembly-1 to Assembly-4 from this work present very close uncertainties, about 2.2 and $2.3 \%$. Whereas the uncertainties not originated from the fission yields are in agreement with reference [16], the ones due the fission yields are ten times larger. The nuclear data considered in reference [16] come from the SCALE 6.2.1 package, where the covariance matrices for the nuclear data (except fission yields) are based on the ENDF/B-VII.1 library, as in the present work. For fission yields, different libraries are used: ENDF/B-VII.1 for the standard deviations and an in-house correlation matrix for the present work, and the covariance matrix from reference [31] for reference [16]. The latest covariance matrix is based on a reduction of independent fission yields using the information from cumulative yields. Such reduction of standard deviations, more than differences in correlation matrices is certainly at the origin of the presented discrepancies. Such results emphasize again the importance of a proper covariance evaluation for the fission yields (both independent and cumulative) for SNF characteristics. 
Table 3. Comparisons with the uncertainties presented in reference [26] for a PWR case, $4.1 \mathrm{wt} . \%$ enrichment, UO fuel, exposure of $40 \mathrm{MWd} / \mathrm{tHM}$ without cooling (case 1), and with reference [11] for a PWR case, $3.4 \%$ enrichment, UO fuel, exposure of $54 \mathrm{MWd} / \mathrm{kgU}$, with 10 years cooling (case 2).

\begin{tabular}{lccccc}
\hline Isotope & \multicolumn{4}{c}{ Uncertainty (\%) } \\
\cline { 2 - 3 } & \multicolumn{2}{c}{ Case 1 } & & \multicolumn{2}{c}{ Case 2 } \\
\cline { 2 - 3 } \cline { 5 - 6 } & {$[26]$} & This work & & {$[11]$} & This work \\
\hline${ }^{234} \mathrm{U}$ & - & 1.8 & & 2.4 & 2.1 \\
${ }^{235} \mathrm{U}$ & 1.0 & 1.4 & & 3.3 & 2.7 \\
${ }^{236} \mathrm{U}$ & 1.5 & 1.6 & & 1.5 & 1.6 \\
${ }^{239} \mathrm{Pu}$ & 2.0 & 2.3 & & 2.9 & 2.6 \\
${ }^{240} \mathrm{Pu}$ & 1.9 & 2.3 & & 2.5 & 2.2 \\
${ }^{241} \mathrm{Pu}$ & 2.7 & 1.7 & & 2.7 & 2.1 \\
${ }^{242} \mathrm{Cm}$ & 2.2 & 2.7 & & 3.6 \\
${ }^{244} \mathrm{Cm}$ & 8.5 & 9.7 & & 9.6 & 9.1 \\
${ }^{90} \mathrm{Sr}$ & 5.0 & 0.7 & & 1.5 & 0.7 \\
${ }^{99} \mathrm{Tc}$ & 9.5 & 1.3 & & 10 & 1.5 \\
${ }^{129} \mathrm{I}$ & 13 & 2.5 & - & 2.9 \\
${ }^{137} \mathrm{Cs}$ & 1.7 & 7 & 4.0 & 6.2 \\
${ }^{148} \mathrm{Nd}$ & 14 & 0.4 & 0.4 & 0.4 \\
\hline
\end{tabular}

\subsection{Activity, neutron and gamma sources}

Regarding the three quantities such as the activities and the neutron/gamma sources for the SNF, the open-source literature on the calculated uncertainties due to nuclear data is very limited or nonexistent for LWRs. Therefore no comparisons are presented here.

\subsection{Isotope inventory}

Studies on the calculated uncertainties for the isotopic vectors are well covered in the literature, often for singleassembly systems. In the following, we will compare our results with the ones presented in reference [26] for a PWR single-assembly calculation $\left(\mathrm{UO}_{2}, 4.1 \mathrm{wt} . \%, 40 \mathrm{MWd} / \mathrm{tHM}\right.$, $15 \times 15$, no cooling, called "case 1 " in the following), and with reference [11] for a specific assembly from the PWR-2 power plant, $\left(\mathrm{UO}_{2}, 3.4 \%, 54 \mathrm{MWd} / \mathrm{kgU}, 15 \times 15,10\right.$ years cooling, called "case 2"' in the following). A few assemblies in the present work can match the characteristics of the case 1 , and a single representative one is selected, results are presented in Table 3. For case 2, the same assembly is considered and results are presented for the same nuclear data libraries ENDF/B-VII.1.

\subsubsection{Case 1}

The agreement for the uncertainties on actinides is rather good, given that different methods and different nuclear data libraries are considered (in Ref. [26], the SCALE-6.1 library is used, being created from various sources for neutron cross sections). For fission products, the differences are more striking, showing again the impact of the fission yields: as no fission yield covariance matrix was available in SCALE-6.1, the authors of reference [26] used the one from ENDF/B-VII.1 which did not contain correlation elements.

\subsubsection{Case 2}

The comparison with reference [11] presents the advantages that many assumptions are shared with the present work. It is based on the same method of uncertainty propagation at the CASMO level (with the SHARK-X tool), using the same nuclear data library for cross sections (ENDF/B-VII.1), the same assembly and the same irradiation history. The only noticeable differences are that reference [11] is based on CASMO simulations only (therefore using reflective boundaries), whereas the present work considers the real assembly environment, based on CASMO/SIMULATE, and that the fission yield uncertainties are different (based on JEFF-3.1.1 in Ref. [11] and ENDF/B-VII.1 in this work). The difference concerning the fission yield uncertainties is mainly affecting the fission product uncertainties and not the actinide uncertainties. As presented in Table 3, the uncertainties for the actinides are very close, with an apparent systematic difference of $10 \%$ (lower in the present case). This small difference might come from the reflective boundary assumption in reference [11]. One should notice that such an assumption can have different impacts depending on the real surrounding of the considered assemblies. Again, in the case of fission products, noticeable differences can be observed, to a large extent due to the fission yield library considered to perform the sampling. As already mentioned in references $[10,7]$, there is a need of developing a reliable covariance matrix for fission yields in the context of SNF applications. The results based on evaluated or user-created fission yield covariance matrices still present strong variations for calculated quantities, indicating the necessity of additional efforts from the nuclear data evaluation community.

\section{Future studies}

The results presented in this paper are representative of three specific reactor cores, two PWR and one BWR. It is a demonstration that the uncertainty study on SNF can be realized on a rather large scale, taking into account the specific irradiation and cooling details of each single assembly. Obviously additional work can be done based on the proposed method for a dedicated reactor, specific nuclear data libraries (especially for fission yields), possible data assimilation as presented in reference [32] to reduce calculate uncertainties, and also the application of the present methodology to burnup credit for SNF repository.

One can also notice that these results are depending on the selection of covariance information. The use of the covariance files from another nuclear data library might change some uncertainties. Additionally, some cross-isotope correlations are not included in the present libraries, but they 
will certainly have an impact on the calculated uncertainties. Such effects can be explored in the future. In the near future, we plan to apply the present method in a systematic manner for each Swiss reactor core and all assembly-cycles. This will complement the PSI database used in core loading licensing. Alternatively, this chain of calculation can be used to provide isotope concentrations for each rod of any assembly to a Monte Carlo transport code such as MCNP. Given a specific canister design, criticality calculations can be performed in a consistent manner with other SNF quantities. We also plan to test this approach in the context of a Swiss canister for final repository of SNF [22].

Finally, the influence of numerical biases on the estimated uncertainties remain to be investigated and will certainly be subject of follow up work in the coming years.

\section{Conclusion}

This paper is a demonstration that the uncertainties due to nuclear data for SNF quantities can be systematically calculated in the case of Swiss reactor cores (both PWR and BWR), taking into account validated assembly histories. This work is based on validated models for CASMO and SIMULATE, with a later addition of the $S N F$ code. A total of about 9200 assembly-cycles were considered, allowing to span wide ranges of fuel enrichments and assembly burnup values. The main conclusion is that the nuclear data have a non-negligible impact on decay heat, activity, neutron and gamma sources, as well as on isotopic inventories.

The comparison with the literature data based on full core simulations show good agreement when the variation of cross sections is concerned, but differences when the variation of fission yields is considered. This is mainly due to the differences in nuclear data libraries for fission yield covariances.

In the future, such an approach can be used in a systematic manner for all assemblies used in a Swiss reactors. The information on the SNF isotopic inventory (with uncertainties), which can be calculated at the nodal level, can also be passed to a transport code such as MCNP to perform criticality calculations for transport and storage casks, thus allowing to perform radiation and criticality calculations based on the same sources of information for both nominal values and uncertainties.

This work was conducted in the framework of the STARS program (http://www.psi.ch/stars) and was partly supported by Swissnuclear, the nuclear energy section of the Swiss electricity companies.

\section{References}

1. J.J. Herrero, A. Vasiliev, M. Pecchia, H. Ferroukhi, S. Caruso, Review calculations for the OECD/NEA Burn-up Credit Criticality Safety Benchmark, Ann. Nucl. Energy 87, 48 (2016)

2. D.L. Watson, J.S. Busch, H.L. Julien, J.S. Ritchie, Optimization of mine layout for nuclear fuel assembly storage, Nucl. Eng. Des. 67, 349 (1982)
3. S. Caruso, Estimation of the radionuclide inventory in LWR spent fuel assembly structural materials for long-term safety analysis, EPJ Nuclear Sci. Technol. 2, 4 (2016)

4. A.J. Koning, D. Rochman, Towards sustainable nuclear energy: putting nuclear physics to work, Ann. Nucl. Energy 35, 2024 (2008)

5. B. Zaffora, M. Magistris, G. Saporta, F. La Torre, Statistical sampling applied to the radiological characterization of historical waste, EPJ Nuclear Sci. Technol. 2, 34 (2016)

6. O. Leray, H. Ferroukhi, M. Hursin, A. Vasiliev, D. Rochman, Methodology for core analyses with nuclear data uncertainty quantification and application to Swiss PWR operated cycles, Ann. Nucl. Energy 110, 547 (2017)

7. D. Rochman, O. Leray, M. Hursin, H. Ferroukhi, A. Vasiliev, A. Aures, F. Bostelmann, W. Zwermann, O. Cabellos, C.J. Diez, J. Dyrda, N. Garcia-Herranz, E. Castro, S. van der Marck, H. Sjostrand, A. Hernandez, M. Fleming, J.-Ch. Sublet, L. Fiorito, Nuclear data uncertainties for typical LWR fuel assemblies and a simple reactor core, Nucl. Data Sheets 139, 1 (2017)

8. O. Cabellos, E. Castro, C. Ahnert, C. Holgado, Propagation of nuclear data uncertainties for PWR core analysis, Nucl. Eng. Technol. 46, 299 (2014)

9. M.B. Chadwick, M. Herman, P. Oblozinsky, M.E. Dunn, Y. Danon, A.C. Kahler, D.L. Smith, B. Pritychenko, G. Arbanas, R. Arcilla, R. Brewer, D.A. Brown, R. Capote, A.D. Carlson, Y.S. Cho, H. Derrien, K. Guber, G.M. Hale, S. Hoblit, S. Holloway, T.D. Johnson, T. Kawano, B.C. Kiedrowski, H. Kim, S. Kunieda, N.M. Larson, L. Leal, J.P. Lestone, R.C. Little, E.A. McCutchan, R.E. MacFarlane, M. MacInnes, C.M. Mattoon, R.D. McKnight, S.F. Mughabghab, G.P.A. Nobre, G. Palmiotti, A. Palumbo, M.T. Pigni, V.G. Pronyaev, R.O. Sayer, A.A. Sonzogni, N.C. Summers, P. Talou, I.J. Thompson, A. Trkov, R.L. Vogt, S.C. van der Marck, A. Wallner, M.C. White, D. Wiarda, P.G. Young, ENDF/B-VII.1 nuclear data for science, technology: cross sections, covariances, fission product yields and decay data, Nucl. Data Sheets 112, 2887 (2011)

10. D. Rochman, O. Leray, A. Vasiliev, H. Ferroukhi, A.J. Koning, M. Fleming, J.C. Sublet, A Bayesian Monte Carlo method for fission yield covariance information, Ann. Nucl. Energy 95, 125 (2016)

11. O. Leray, D. Rochman, P. Grimm, H. Ferroukhi, A. Vasiliev, M. Hursin, G. Perret, A. Pautz, Nuclear data uncertainty propagation on spent fuel nuclide compositions, Ann. Nucl. Energy 94, 603 (2016)

12. R.E. MacFarlane, A.C. Kahler, Methods for Processing ENDF/B-VII with NJOY, Nucl. Data Sheets 111, 2739 (2010)

13. O. Leray, P. Grimm, M. Hursin, H. Ferroukhi, A. Pautz, Uncertainty quantification of spent fuel nuclide compositions due to cross-sections, decay constants and fission yields, in Proceedings of the PHYSOR-2014 Conference (The Westin Miyako, Kyoto, Japan, 2014)

14. J. Rhodes, K. Smith, D. Lee, CASMO-5 development and applications, in Proceedings of the PHYSOR-2006 conference, ANS Topical Meeting on Reactor Physics (Vancouver, BC, Canada, 2006), p. B144

15. W. Wieselquist, A. Vasiliev, H. Ferroukhi, Nuclear data uncertainty propagation in a lattice physics code using stochastic sampling, in Proceedings of the PHYSOR-2012 conference, Advances in Reactor Physics Linking 
Research, Industry, and Education, on CD-ROM, (American Nuclear Society, Knoxville, Tennessee, USA, 2012), pp. $15-20$

16. G. Ilas, H. Lijenfeldt, Decay heat uncertainty for BWR used fuel due to modeling and nuclear data uncertainties, Nucl. Eng. Des. 319, 176 (2017)

17. D. Rochman, A.J. Koning, D.F. Da Cruz, Propagation of U and $\mathrm{Pu}$ nuclear data uncertainties for a typical PWR fuel element, Nucl. Technol. 179, 323 (2012)

18. H. Ferroukhi, O. Leray, M. Hursin, A. Vasiliev, G. Perret, A. Pautz, Study of nuclear decay data contribution to uncertainties in heat load estimations for spent fuel pools, Nucl. Data Sheets 118, 498 (2014)

19. T. Bahadir, S.O. Lindahl, Studsvik's next generation nodal code SIMULATE-5, in Proceedings of the ANFM-2009 conference, Advances in Nuclear Fuel Management IV (Hilton Head Island, South Carolina, USA, 2009)

20. S. Borresen, Spent nuclear fuel analyses based on in-core fuel management calculations, in Proceedings of the PHYSOR-2014 conference (The Westin Miyako, Kyoto, Japan, 2014)

21. R.A. Fisher, The moments of the distribution for normal samples of measures of departure from normality, in Proceedings of the Royal Society (London, 1931), Vol. 130, p. 16

22. H. Hotelling, New light on the correlation coefficient and its transforms. J. R. Stat. Soc. B 15, 193 (1953)

23. D. Rochman, Scoping Analyses towards Global Methodology for CASMO Uncertainty and Bias Quantification - Case Study for KKG UR3 Sample, PSI Technical Report TM-4115-09 V.1, 2016
24. D. Rochman, E. Bauge, A. Vasiliev, H. Ferroukhi, Correlation nu-sigma-chi in the fast neutron range via integral information, EPJ Nuclear Sci. Technol. 3, 14 (2017)

25. Decay Heat Power in Light Water Reactors, ANSI/ANS-5.12014 (American Nuclear Society, 2014)

26. W. Zwermann, A. Aures, L. Gallner, V. Hannstein, B. KrykaczHaussmann, K. Velkov, J.S. Martinez, Nuclear data uncertainty and sensitivity analysis with XSUSA for fuel assembly depletion calculations, Nucl. Eng. Technol. 46, 343 (2014)

27. M.L. Williams, G. Ilas, W.J. Marshall, B.T. Rearden, Applications of nuclear data covariances to criticality safety and spent fuel characterization, Nucl. Data Sheets 118, 341 (2014)

28. J. Hu, I.C. Gauld, Impact of nuclear data uncertainties on calculated spent fuel nuclide inventories and advances NDA instrument response, ESARDA Bull. 51 (2014)

29. D. Rochman, C.M. Sciolla, Nuclear data uncertainty propagation for a typical PWR fuel assembly with burnup, Nucl. Eng. Technol. 46, 353 (2014)

30. D.F. da Cruz, D. Rochman, A.J. Koning, Quantification of Uncertainties due to $\mathrm{U}, \mathrm{Pu}$ and Fission Products Nuclear Data Uncertainties for a PWR Fuel Assembly, Nucl. Data Sheets 118, 531 (2014)

31. M.T. Pigni, M.W. Francis, I.C. Gault, Investigation of inconsistent ENDF/B-VII.1 independent and cumulative fission product yields with proposed revisions, Nucl. Data Sheets 123, 231 (2015)

32. Y. Kawamoto, G. Chiba, Feasibility study of decay heat uncertainty reduction using nuclear data adjustment method with experimental data, J. Nucl. Sci. Technol. 54, 213 (2017)

Cite this article as: Dimitri A. Rochman, Alexander Vasiliev, Abdelhamid Dokhane, Hakim Ferroukhi, Uncertainties for Swiss LWR spent nuclear fuels due to nuclear data, EPJ Nuclear Sci. Technol. 4, 6 (2018) 


\section{Appendix A: Tables of uncertainties}

For convenience, the maximum uncertainties due to all considered nuclear data in percent are provided in this Appendix. They correspond to the maximum values presented in the previous figures, as one sigma.

Table A.1. Maximum uncertainty $(1 \sigma)$ in $\%$ for the fuel exposure for the different core types and fuel.

\begin{tabular}{lclll}
$\begin{array}{l}\text { Burnup } \\
\mathrm{MWd} / \mathrm{kgU}\end{array}$ & All & $\begin{array}{l}\mathrm{BWR}_{\mathrm{UO}} \\
\mathrm{UO}_{2}\end{array}$ & $\begin{array}{l}\mathrm{PWR}_{\mathrm{UO}_{2}} \\
5\end{array}$ & $\begin{array}{l}\mathrm{PWR} \\
\mathrm{MOX}\end{array}$ \\
\hline 10 & 1.30 & 0.00 & 1.14 & 1.30 \\
15 & 2.17 & 0.39 & 2.17 & 1.58 \\
20 & 2.25 & 0.64 & 2.25 & 1.24 \\
25 & 1.65 & 0.45 & 1.65 & 1.22 \\
30 & 1.66 & 0.48 & 1.66 & 1.09 \\
35 & 1.67 & 0.41 & 1.67 & 1.59 \\
40 & 1.63 & 0.32 & 1.63 & 1.53 \\
45 & 1.39 & 0.31 & 1.39 & 1.24 \\
50 & 1.22 & 0.24 & 1.22 & 1.07 \\
55 & 1.29 & 0.21 & 1.29 & 1.19 \\
60 & 1.11 & 0.16 & 1.11 & 0.49 \\
\hline
\end{tabular}

Table A.2. Maximum uncertainty $(1 \sigma)$ in $\%$ for the decay heat for the different core types and fuel.

\begin{tabular}{lllll}
\hline $\begin{array}{l}\text { Cooling time } \\
\text { years }\end{array}$ & All & $\begin{array}{l}\mathrm{BWR}_{\mathrm{UO}} \\
\mathrm{UO}_{2}\end{array}$ & $\begin{array}{l}\mathrm{PWR}^{\mathrm{UO}} \\
\mathrm{UO}_{2}\end{array}$ & $\begin{array}{l}\mathrm{PWR} \\
\mathrm{MOX}\end{array}$ \\
0.5 & 3.38 & 3.10 & 3.38 & 1.76 \\
2 & 5.20 & 4.68 & 5.20 & 2.74 \\
4 & 6.99 & 6.28 & 6.99 & 4.66 \\
6 & 7.11 & 6.39 & 7.11 & 5.12 \\
8 & 6.27 & 5.42 & 6.27 & 4.39 \\
10 & 5.13 & 3.95 & 5.13 & 3.59 \\
20 & 4.92 & 3.52 & 4.92 & 3.25 \\
50 & 4.74 & 3.54 & 4.74 & 2.91 \\
100 & 4.63 & 3.44 & 4.63 & 2.33 \\
200 & 4.28 & 2.95 & 4.28 & 1.40 \\
500 & 3.92 & 2.48 & 3.92 & 1.12 \\
1000 & 3.94 & 2.87 & 3.94 & 1.15 \\
5000 & 3.53 & 2.91 & 3.53 & 1.15 \\
$10 \mathrm{k}$ & 2.75 & 2.75 & 2.51 & 1.49 \\
$20 \mathrm{k}$ & 2.72 & 2.72 & 2.44 & 1.51 \\
$50 \mathrm{k}$ & 2.70 & 2.70 & 2.41 & 1.57 \\
$100 \mathrm{k}$ & 2.69 & 2.69 & 2.39 & 1.63 \\
$200 \mathrm{k}$ & 2.28 & 2.28 & 2.12 & 1.43 \\
$500 \mathrm{k}$ & 2.58 & 2.58 & 2.58 & 1.46 \\
\hline & 2.48 & 2.47 & 2.48 & 1.38 \\
\hline
\end{tabular}

Table A.3. Maximum uncertainty $(1 \sigma)$ in $\%$ for the activity for the different core types and fuel.

\begin{tabular}{lllll}
\hline $\begin{array}{l}\text { Cooling time } \\
\text { years }\end{array}$ & All & $\begin{array}{l}\mathrm{BWR} \\
\mathrm{UO}_{2}\end{array}$ & $\begin{array}{l}\mathrm{PWR} \\
\mathrm{UO}_{2}\end{array}$ & $\begin{array}{l}\mathrm{PWR} \\
\mathrm{MOX}\end{array}$ \\
\hline 0.1 & 1.91 & 1.61 & 1.91 & 1.54 \\
0.5 & 2.34 & 2.34 & 2.11 & 1.83 \\
2 & 3.07 & 3.07 & 2.91 & 2.47 \\
4 & 3.69 & 3.07 & 3.69 & 2.56 \\
6 & 4.41 & 3.07 & 4.41 & 2.48 \\
8 & 4.77 & 3.47 & 4.77 & 2.41 \\
10 & 4.98 & 3.68 & 4.98 & 2.43 \\
20 & 5.36 & 4.04 & 5.36 & 2.71 \\
50 & 5.61 & 4.29 & 5.61 & 3.27 \\
100 & 5.67 & 4.35 & 5.67 & 3.37 \\
200 & 5.19 & 3.94 & 5.19 & 1.96 \\
500 & 3.39 & 2.65 & 3.39 & 1.15 \\
1000 & 3.13 & 2.66 & 3.13 & 1.17 \\
5000 & 2.43 & 2.43 & 2.31 & 1.61 \\
$10 \mathrm{k}$ & 2.35 & 2.35 & 2.25 & 1.61 \\
$20 \mathrm{k}$ & 2.27 & 2.27 & 2.15 & 1.58 \\
$50 \mathrm{k}$ & 2.19 & 2.19 & 2.09 & 1.57 \\
$100 \mathrm{k}$ & 1.74 & 1.63 & 1.74 & 1.25 \\
$200 \mathrm{k}$ & 2.00 & 2.00 & 1.76 & 1.30 \\
$500 \mathrm{k}$ & 2.00 & 2.00 & 1.72 & 1.26 \\
\hline
\end{tabular}

Table A.4. Maximum uncertainty $(1 \sigma)$ in $\%$ for the neutron source for the different core types and fuel.

\begin{tabular}{lcccr}
\hline $\begin{array}{l}\text { Cooling time } \\
\text { years }\end{array}$ & All & $\begin{array}{c}\mathrm{BWR}_{\mathrm{UO}} \\
\mathrm{UO}_{2}\end{array}$ & $\begin{array}{l}\mathrm{PWR} \\
\mathrm{UO}_{2}\end{array}$ & $\begin{array}{r}\mathrm{PWR} \\
\mathrm{MOX}\end{array}$ \\
\hline 0.1 & 10.17 & 5.19 & 10.17 & 5.62 \\
0.5 & 11.20 & 5.36 & 11.20 & 6.36 \\
2 & 12.53 & 6.84 & 12.53 & 8.76 \\
4 & 13.27 & 7.30 & 13.27 & 9.16 \\
6 & 13.24 & 7.29 & 13.24 & 9.18 \\
8 & 13.11 & 7.24 & 13.11 & 9.11 \\
10 & 12.98 & 7.19 & 12.98 & 9.01 \\
20 & 12.54 & 7.03 & 12.54 & 8.69 \\
50 & 11.97 & 6.62 & 11.97 & 8.21 \\
100 & 11.03 & 6.63 & 11.03 & 8.29 \\
200 & 16.05 & 10.75 & 16.05 & 14.40 \\
500 & 17.55 & 11.36 & 17.55 & 15.50 \\
1000 & 18.11 & 11.53 & 18.11 & 15.97 \\
5000 & 18.28 & 11.54 & 18.28 & 16.14 \\
$10 \mathrm{k}$ & 16.54 & 10.63 & 16.54 & 14.86 \\
$20 \mathrm{k}$ & 9.29 & 6.32 & 9.29 & 9.15 \\
$50 \mathrm{k}$ & 7.51 & 3.61 & 7.51 & 6.08 \\
$100 \mathrm{k}$ & 7.62 & 3.37 & 7.62 & 5.68 \\
$200 \mathrm{k}$ & 7.63 & 3.38 & 7.63 & 5.64 \\
$500 \mathrm{k}$ & 7.61 & 3.36 & 7.61 & 5.57 \\
\hline & & & &
\end{tabular}


Table A.5. Maximum uncertainty $(1 \sigma)$ in $\%$ for the gamma source for the different core types and fuel.

\begin{tabular}{lllll}
\hline $\begin{array}{l}\text { Cooling time } \\
\text { years }\end{array}$ & All & $\begin{array}{l}\mathrm{BWR} \\
\mathrm{UO}_{2}\end{array}$ & $\begin{array}{l}\mathrm{PWR}_{\mathrm{UO}_{2}} \\
0.1\end{array}$ & $\begin{array}{l}\mathrm{PWR} \\
\mathrm{MOX}\end{array}$ \\
0.5 & 4.27 & 4.00 & 4.27 & 2.78 \\
2 & 6.78 & 5.85 & 6.78 & 4.77 \\
4 & 8.65 & 7.85 & 8.65 & 7.43 \\
6 & 8.97 & 8.00 & 8.97 & 8.80 \\
8 & 8.49 & 7.11 & 8.08 & 8.49 \\
10 & 6.91 & 5.39 & 6.78 & 6.91 \\
20 & 5.88 & 4.13 & 5.88 & 5.69 \\
50 & 5.52 & 4.24 & 5.52 & 5.38 \\
100 & 5.48 & 4.31 & 5.48 & 5.07 \\
200 & 5.54 & 4.33 & 5.54 & 4.26 \\
500 & 5.39 & 4.08 & 5.39 & 2.16 \\
1000 & 4.81 & 3.13 & 4.81 & 1.32 \\
5000 & 4.75 & 3.08 & 4.75 & 1.51 \\
$10 \mathrm{k}$ & 5.82 & 4.08 & 5.82 & 4.43 \\
$20 \mathrm{k}$ & 5.76 & 4.04 & 5.76 & 4.42 \\
$50 \mathrm{k}$ & 4.67 & 3.34 & 4.67 & 3.87 \\
$100 \mathrm{k}$ & 3.55 & 2.68 & 3.55 & 3.08 \\
$200 \mathrm{k}$ & 2.76 & 2.44 & 2.76 & 1.80 \\
$500 \mathrm{k}$ & 2.57 & 2.57 & 2.37 & 1.40 \\
\hline & 2.48 & 2.48 & 2.25 & 1.27 \\
\hline
\end{tabular}

